\title{
DESENVOLVIMENTO SUSTENTÁVEL FRENTE À RESPONSABILIDADE SOCIAL DAS ORGANIZAÇÕES EMPRESARIAIS
}

\author{
André Francisco Cantanhede de Menezes ${ }^{1}$
}

\begin{abstract}
RESUMO
Este artigo tem por objetivo analisar como o princípio do desenvolvimento sustentável se comporta como fator de obtenção do justo equilíbrio entre as exigências socioambientais e as da atividade econômica, com base na responsabilidade social das organizações empresariais. Trata-se de pesquisa com método exploratório, abordagem qualitativa e delineamento documental. Conclui-se que as organizações, mesmo ainda objetivando o lucro, podem praticar a livre iniciativa com vista a exercer sua função social, o que lhe dá vantagem no cenário competitivo, pois a própria sociedade consumidora e usufrutuária dos bens e serviços pela organização produzidos e disponibilizados, reclama tal comportamento.
\end{abstract}

Palavras-chave: Desenvolvimento sustentável. Empresa. Livre iniciativa. Organizações. Responsabilidade social.

\section{SUSTAINABLE DEVELOPMENT AGAINST THE SOCIAL RESPONSIBILITY OF BUSINESS ORGANIZATIONS}

\begin{abstract}
This article aims to analyze how sustainable development behaves as a recovery factor of the balance between socio-environmental and economic activities, based on the social responsibility of business organizations. It is a research with the exploratory method, qualitative approach and documentary delineation. Concluding, how organizations, even so aiming for profit, can practice free initiative in order to exercise their social function, which gives them competitive advantage, made available, claims such behavior.
\end{abstract}

\footnotetext{
${ }^{1}$ Doutorando em Direito pela Universidade de Marília. Mestre em Gestão e Desenvolvimento Regional pela Universidade de Taubaté (2018). Pós-graduado em Direito Ambiental (2014) e Direito e Processo Penal (2014) e graduado em Direito (2012) pela Faculdade de Imperatriz. Professor universitário na Universidade Federal do Maranhão e na Universidade Estadual do Tocantins. Advogado.e-mail: andrefcmenezes@gmail.com
} 
Keywords: Company. Free Initiative. Organizations. Social responsability. Sustainable development.

\section{INTRODUÇÃO}

Ao se enveredar pela teoria das organizações socioprodutivas, há muito, especialmente em razão do modelo capitalista, permeia entre nós a dicotomia entre a exploração de atividade econômica por organizações empresariais e os impactos socioambientais dela decorrentes. Com efeito, essa discussão encontra fundo naquilo que hoje por bem se pactuou chamar de desenvolvimento sustentável, como argumento (em tese) apto para se aferir responsabilidade social das organizações, frente à conduta destas.

Tomando por base esse problema, este trabalho tem por objetivo analisar o princípio do desenvolvimento sustentável como fator de obtenção do justo equilíbrio entre as exigências socioambientais e as da atividade econômica, ante a responsabilidade social das organizações empresariais.

Justifica-se esta pesquisa, pois, a partir das premissas trazidas na Constituição de 1988, em especial, aquelas descritas no seu art. 170, vislumbra-se a dificuldade de acomodar, a um só tempo, propriedade e livre iniciativa para o exercício de atividade econômica, com anseios sociais atinentes ao bem-estar comum, como, por exemplo, a função social da propriedade, redução das desigualdades regionais e sociais, bem ainda, a defesa do meio ambiente.

Trata-se de pesquisa com método exploratório, com abordagem qualitativa e com delineamento a partir da verificação documental. Para isso, definiu-se e após, relacionou-se expressões como desenvolvimento sustentável, responsabilidade social, organização e empresa, esta, além de atividade econômica organizada, espécie de organização. Por fim, as bases conceituais foram relacionadas entre o Direito e a Administração.

No desenvolvimento, traça-se considerações acerca do que é desenvolvimento sustentável, sobretudo, frente à definição apresentada, em 1987, pela Comissão Mundial sobre o Meio Ambiente e Desenvolvimento (instituída pela Organização das Nações Unidas-ONU), por meio do documento chamado Nosso Futuro Comum, também conhecido como Relatório Brundtland. Assenta-se o que são organizações e suas facetas, nos dois sentidos da expressão (a saber: dar determinada ordem a algo, arrumar, estruturar; e outro, em que organização se trasmuda, em qualquer instituição, ente), para então analisar a teoria da empresa, esta entendida como o exercício da atividade empresarial e, por consequência, na linha do art. 966, do Código Civil, atividade econômica. Com base nisso, discorre-se ser a empresa (sentido comum) uma 
organização econômica e social e, dessa feita, a organização empresária, em que pese amoldarse à propriedade privada, é detentora de responsabilidades sociais. O exemplo disso ilustra-se através dos steakholders. Seguindo-se, essa responsabilidade é analisada sob o prisma, tanto da Administração como do Direito, pois, pulsante o estágio pós-convencional desenvolvimento moral e dever de observância à função social da propriedade.

Conclui-se que, graças ao advento de uma maior exigibilidade das responsabilidades sociais das organizações empresariais, estas, sem perderem seu objetivo precípuo que é a geração de lucro, mais inclinadas se mostram à prática da atividade econômica pautada pelo princípio do desenvolvimento sustentável, em especial, com escopo de alargar seu potencial competitivo.

\section{DESENVOLVIMENTO SUSTENTÁVEL}

Empiricamente, em especial considerado o senso-comum, dessume-se que a expressão desenvolvimento sustentável é tida como estandarte de uma sociedade fenotípica que, sobretudo no seio daqueles que exercem atividade econômica, para ilidir sua parcela de culpa pela degradação do meio ambiente (seja em qualquer de suas facetas), bradam esse slogam, como se salvo-conduto fosse, para práticas controversas. É de se dizer: em que pese ser um conceito normativo na tentativa de combate a exclusões advindas do crescimento econômico, não se olvida que seu uso fora banalizado, para assim servir apenas como instrumento de marketing.

Nítida a maior afeição dessa terminologia às questões ambientais puras, especialmente para criticar a forma com que o exercício da propriedade privada, além de consumir recursos naturais, produz descartes poluentes quase nunca tratados devidamente. Contudo, o espírito de desenvolvimento sustentável também é expansivo para outras áreas, sobretudo, a social: de modo mais intrínseco, confrontando o desenfreado produzir, visando a todo custo, o lucro, então exclusivo objetivo da organização empresarial. Esta, por poder usufruir dos fatores de produção, há de dar retorno para os que dela fazem parte, bem como, para os que dela dependem indiretamente. Há todo um conjunto de setores (comunidade) que, ao redor da organização empresarial, como se afluentes fossem, a alimentam e, mesmo de modo reflexo, dependem dela.

Assim, emergem os stakeholders (partes interessadas), ou seja, "qualquer grupo ou indivíduo que possa afetar ou ser afetado pela conquista dos objetivos organizacionais" (HOFF, 2008, p. 88). Como exemplo, basta imaginar que para uma multinacional que fabrica e 
comercializa chocolates, além de seus empregados diretos, estão a ela vinculados os empregados da fazenda exportadora da matéria prima, e, por conseguinte, os familiares destes - essa é a engrenagem pautada pela responsabilidade social das organizações, haja vista, a propriedade privada ter de cumprir com sua função social.

É nesse misto de embate entre propriedade privada, fatores de produção, dever moral e ético, que as organizações vem assumindo (ou, ao menos, delas se exige isso) uma nova postura comportamental, consistente na busca por uma riqueza constante: colocar, em paralelo, crescimento econômico, desenvolvimento nacional, proteção ao meio ambiente e ao trabalho, redução das desigualdades regionais e sociais. Com efeito,

\footnotetext{
Conceituado como alternativa à lógica hegemônica de produção de mercadorias através da degradação ambiental e exploração do trabalho humano, o desenvolvimento sustentável encerra um ideal de racionalização na apropriação dos recursos naturais, inserindo uma variável temporal e uma exigência ética no desenvolvimento econômico (VILANI, 2009, p. 68).
}

No caso brasileiro, não se desconsiderando as balizas internacionais, a partir do advento da Constituição Federal em 1988, essa questão, ao menos do ponto de vista jurídico e da gestão empresarial, fora mais exacerbada. É que a Lei Maior, ao tratar da ordem econômica, reza, no parágrafo único do art. 170, ser "assegurado a todos o livre exercício de qualquer atividade econômica"; e o faz após apontar a livre iniciativa como fundamento da República (art. $1^{\circ}$, IV) e colocar a propriedade como direito fundamental (art. $5^{\circ}$, XXII), inclusive, a privada. Vê-se, portanto, nítido incentivo ao comportamento empreendedor, ou seja, àquele que deflagra uma atividade econômica, especialmente, de modo organizado, assumindo riscos e responsabilidades.

Não se está aqui a dizer que tais preceitos são incorretos. Entretanto, há de se enfrentar o outro lado da moeda: é possível manter o crescimento econômico eficiente (sustentado) no longo prazo, acompanhado da melhoria das condições sociais (distribuição de renda, por exemplo) e respeitando o meio ambiente?

Essa pergunta ressoa em grau mais forte, pois, aquele mesmo art. 170, da Constituição, elenca, como princípios da ordem econômica (a serem seguidos, portanto), notadamente, a função social da propriedade, a livre concorrência, a defesa do consumidor, a redução das desigualdades regionais e sociais, bem como, a defesa do meio ambiente, inclusive mediante tratamento diferenciado conforme o impacto ambiental dos produtos e serviços e de seus processos de elaboração e prestação. 
Prima facie, quando se fala em desenvolvimento sustentável, salutar se livrar do entendimento que, não raro, vincula esta expressão unicamente ao contexto ambiental, em sentido estrito, ou seja, à fauna e à flora. Isso, pois, nem mesmo a expressão meio ambiente, comporta uma única acepção e aplicação, tanto que a Constituição, em seu art. 225, traz conotação múltipla.

Aliando-se a isso, a Lei no 6.938/1981 (que dispõe sobre a Política Nacional do Meio Ambiente), em seu art. $3^{\circ}$, apregoa que se entende por "meio ambiente, o conjunto de condições, leis, influências e interações de ordem física, química e biológica, que permite, abriga e rege a vida em todas as suas formas" (inciso I). Desse modo, o meio ambiente, enquanto bem jurídico tutelado, pode ser enquadrado sob cinco prismas diferenciados: natural, artificial, cultural, ambiente do trabalho e patrimônio genético.

Avançando-se, a Comissão Mundial sobre o Meio Ambiente e Desenvolvimento (instituída pela Organização das Nações Unidas-ONU), apresentou, em 1987, documento chamado Nosso Futuro Comum (Relatório Brundtland). Os autores desse relatório consideram que o risco do crescimento econômico deve ser levado a sério, preocupação que se expressa no mote definidor do que deve ser entendido como princípio (pois norteador de condutas) do desenvolvimento sustentável: "aquele que atende às necessidades do presente sem comprometer a possibilidade de as gerações futuras atenderem às suas necessidades" (CGEE, 2012, p. 18).

Nesse sentido, o Supremo Tribunal Federal-STF, em julgado paradigma, assentou que:

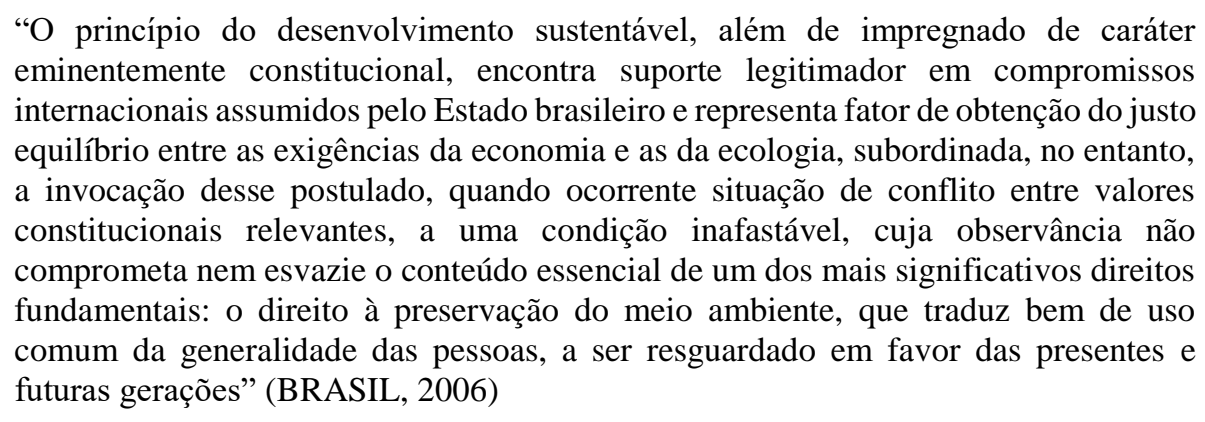

A partir desse conceito, infere-se que o dito crescimento econômico eficiente se figura como condição necessária, porém, não suficiente para elevação do bem-estar humano. Nesse passo, o livre exercício de atividade empresarial, consistente na expressão da propriedade privada, com vista a concretizar o desenvolvimento sustentável, é aquele caracterizado como um processo contínuo de melhoria de condições de vida, no sentido de que cada geração deve deixar para a próxima, proporcionalmente, o mesmo nível de riqueza. Veja-se que, 
Independentemente das teorias econômicas capitalistas que o mundo globalizado vem impondo à sociedade dois pontos merecem destaque, "desenvolvimento" e "sustentabilidade", todas as teorias econômicas capitalistas passam pela ideia de crescimento e desenvolvimento, o problema é que deveria estar incluso neste contexto econômico a palavra sustentabilidade (SOUZA; PEIXOTO, 2018, p. 696).

Por óbvio, além de políticas públicas (atuação do Estado), requer-se que as organizações deixem o estado de inércia, latência (como se máquinas fossem), para assumir, então, uma postura mais organicista, focalizada em compreender e administrar suas necessidades e as relações com o ambiente; e, quiçá, tê-las como cérebros, atentas à importância do processamento de informações, aprendizagem e inteligência, com escopo de maior flexibilidade e inovação.

\section{UMA FORMA DE ORGANIZAÇÃO CHAMADA EMPRESA}

\subsection{Organizações}

Traçando-se uma escala evolutiva, com escopo de se identificar a origem do Estado, ou mais precisamente, da estruturação de um convívio social organizado, não raro se estampa um cenário em que indivíduos se encontravam em total status de liberdade e, ante a necessidade de estabelecer limitações àquelas então plenas e incontestáveis liberdades individuais, os mesmos indivíduos cedem parcela de sua "soberania" pessoal, para formar um novo ente, oriundo do somatório delas, o qual se volta àqueles para organizá-los. Esta simplória explanação (do ponto de vista da teoria geral do Estado, e dos conteúdos do Direito), serve, sobremaneira, para delinear que o fato de haver necessidade de se organizar indica três vetores relevantes, a saber: a organização, pois o ato de estruturar-se e dar ensejo ao novel ente criado; o recurso utilizado para fosse efetivada organização; e, seu objetivo (finalidade). No exemplo apregoado, os vetores podem ser identificados, respectivamente, como o Estado, os indivíduos (e sua vontade), e a regulamentação da vida em sociedade.

Delineada essa circunstância, percebe-se que, além de um Estado (governo), ter-se-á, sempre, uma espécie de organização em toda parte. Pode-se imaginar desde algo mais simplista como um artesão que trabalha com seu auxiliar nos fundos de uma casa; perpassando por estruturas mais complexas como uma universidade, as forças armadas, uma igreja, um partido 
político; bem ainda, desaguando-se em exemplo emblemático, a saber, uma multinacional que fabrica e comercializa hambúrgueres. As organizações não são recentes.

Volvendo-se para o campo da ciência da Administração e alargando-se o espectro de visão, tem-se organização como "a entidade que possibilita que o trabalho em grupo ou equipe seja mais eficaz do que o trabalho individual na consecução de objetivos" (MONTANA; CHARNOV, 2010, p. 170). Cuida-se de

\footnotetext{
"Um sistema socialmente estabelecido pelo conjunto de valores expressos pelos indivíduos que dela fazem parte, sendo assimiladas e transmitidas sucessivamente pelas mesmas, daí a importância e a responsabilidade diante dos outros, das novas gerações" (KANAANE, 1994, p. 30).
}

Com efeito, na lição de Maximiano "uma organização é um sistema de recursos que procura realizar algum tipo de objetivo (ou conjunto de objetivos)"; e segundo ele, "além de objetivos e recursos, as organizações têm dois outros componentes importantes: processos de transformação e divisão do trabalho" (2011, p. 4). Em outras palavras, de posse dos recursos (humanos, materiais, financeiros, de informação e tecnologia, espaço e tempo), dividindo-se o trabalho através de especialização de tarefas, organiza-se uma sequência de atividades interligadas e coordenadas (processo) para que aqueles recursos e trabalho sejam transformados em resultados, gerando-se produtos e/ou serviços, atingindo-se os objetivos propostos.

Nota-se, desse modo, que o termo organização tem, no mínimo, dois sentidos de significância: um, mais intimamente ligado ao próprio verbo organizar, ou seja, dar determinada ordem a algo, arrumar, estruturar; e outro, que aponta a existência de algo materialmente constituído por partes associadas para consecução de um fim comum. Neste particular, intuitivamente, organização se trasmuda, portanto, em qualquer instituição.

\footnotetext{
“As organizações constituem a forma dominante de instituição da moderna sociedade: são a manifestação de uma sociedade altamente especializada e interdependente que se caracteriza por um crescente padrão de vida" (CHIAVENATO, 2003, p. 291).
}

Nessa linha de raciocínio, embrenhando-se no contexto específico deste trabalho, a par daquilo já narrado, descortina-se que uma empresa, ou mais tecnicamente, uma atividade empresarial, amolda-se àquele conceito, pois organização de negócios, que tem objetivo de vender produtos e serviços e obter lucro (MAXIMIANO, 2010, p. 7). Assim, salutar se fazer um recorte para discorrer acerca de aspectos relacionados à atividade empresarial, mais afetos do Direito. 


\subsection{Atividade empresarial}

Na Idade Média, com o crescimento do comércio a partir da intensificação das feiras, surge a profissão de mercador (ou comerciante), e, posteriormente, como fruto dessa prática da mercancia, a burguesia. Frisa-se que atividade comercial não era regulamentada pelo direito comum, sobretudo, pois se tinha um sistema feudal dominante (marcado pelas limitações e formalismos) e os dogmas da Igreja (que não considerava digno ser comerciante). Rompendose com isso, aflora uma teoria subjetiva, marcada pelo uso dos costumes mercantis para solução de conflitos, que considerava comerciante unicamente aqueles que estavam matriculados nas Corporações de Ofício (daí o vínculo subjetivo), e somente estes tinham acesso aos privilégios próprios dos comerciantes.

Por meio dos ideais da Revolução Francesa - liberdade, igualdade e fraternidade -, supera-se o sistema subjetivo, dando azo ao surgimento de um direito unificado para todos que se dedicassem à atividade mercantil: em 1807, o Código Napoleônico implanta a teoria dos atos de comércio e esta prática passa a ser livre. Assim, a classificação do comerciante agora é objetiva, ou seja, o que o torna sujeito um comerciante é a sua atividade: prática de atos de comércio, os quais definidos naquele código, como por exemplo, a compra e venda de mercadorias, atividades financeiras, atividades industriais, etc. (GUIMARÃES, 2016, p. 13).

No Brasil, a partir dessa influência francesa, fora editado, em 1850, o Código Comercial (Lei $n^{\circ}$ 556/1850). Ocorre que manifesta era dificuldade em traçar uma definição para ato de comércio capaz de abranger todas as atividades comerciais, o que gerou, na doutrina, comentários críticos àquela teoria objetiva.

Em paralelo a isso, havia na Itália um processo de unificação dos direitos civil e comercial, que fora concretizado em 1942 e trouxe como efeito, o surgimento da Teoria da Empresa, superando o conceito objetivo de comerciante que o identificava como sendo quem praticava atos de comércios.

Para esta teoria, qualquer atividade pode ser considerada empresária; tudo vai depender da forma como ela é exercida. Não há mais um rol de atividades consideradas comerciais ou não. Esta teoria também abandona o conceito de comerciante e passa a usar o de empresário. No Direito pátrio, a Lei $\mathrm{n}^{\circ} 10.406 / 2002$, ao passo que revogou grande parte daquele Código Comercial (Lei n ${ }^{\circ} 556 / 1850$ ), instituiu o Código Civil.

Este, por sua vez, como assinalado, reza em seu artigo 966, que considera-se empresário quem exerce profissionalmente atividade econômica organizada para a produção ou a circulação de bens ou de serviços. Veja-se que o que se conceitua é o empresário, e não, 


\section{DESENVOLVIMENTO SUSTENTÁVEL FRENTE À RESPONSABILIDADE SOCIAL DAS ORGANIZAÇÕES EMPRESARIAIS}

empresa; não obstante, esta há de se entendida como uma atividade exercida. Com efeito, Bulgarelli definiu empresa como "atividade econômica organizada de produção e circulação de bens e serviços para o mercado, exercida pelo empresário, em caráter profissional, através de um complexo de bens" (1995, p.100).

\subsection{Empresa como organização}

Retomando, aliando-se Administração e Direito, com certa tranquilidade se pode afirmar, pela comparação de seus respectivos conceitos, que empresa (exercício de atividade econômica pelo empresário) é uma espécie de organização, pois naquela, há um sistema de recursos que através de divisão do trabalho e de processos de transformação, visa atingir objetivos.

Como bem observa Guimarães, referindo-se ao art. 2.082 do Código Civil italiano de 1942, percebe-se que este diploma incorporou à teoria da empresa, a necessidade de uma figura que se aplicasse a todas as formas de atividades econômicas, razão pela qual, "a empresa foi, então, introduzida nesse contexto como sendo uma relação entre atividade econômica e organização" (2016, p. 20). E, de fato, o é, máxime, pois,

\footnotetext{
“a empresa é um organismo econômico que sob o seu próprio risco, recolhe e põe em atuação sistematicamente os elementos necessários para obter um produto destinado à troca. A combinação dos fatores (natural, capital e trabalho) que associados produzem resultados impossíveis de serem alcançados individualmente, e o risco, que o empresário assume ao produzir uma nova riqueza são requisitos indispensáveis a toda empresa" (BULGARELLI, 1985, p.25).
}

O aspecto organizacional - em seus dois sentidos alhures já mencionados -, é tão marcante à caracterização do empresário, que o parágrafo único, do art. 966, do Código Civil, traz uma exceção dentro da própria exceção: abrange atividades econômicas que, embora organizadas para produção ou circulação de bens ou serviços com intuito lucrativo, ficaram fora do alcance jurídico das normas reguladoras da empresa. Isso, pois, quando a atividade intelectual (de qualquer natureza) está absorvida pela estrutura organizacional da empresa, essa atividade intelectual fará parte dos fatores de produção, juntamente com o capital, mão de obra e organização, caracterizando a prática de um ato de empresa.

Se de um lado Maximiliano atribui à empresa característica de ser uma organização de negócios, mais voltada para o aspecto econômico em si, notadamente, pois, "tem objetivo de vender produtos e serviços e obter lucro" (2010, p. 7), de outro, pertinente também se mostra o argumento de Chiavenato que, agarrando-se à teoria clássica de Henri Fayol, estampa a 
organização como entidade social, haja vista, como empreendimento humano que é, "pessoas interagem entre si para alcançar objetivos específicos” (2003, p. 82).

Essa dita pertinência para se atribuir à empresa dupla conotação quanto sua classificação como organização, promove a possibilidade de se estabelecer análise da responsabilidade social de uma organização empresarial, justamente através da dialética entre os aspectos econômico e social.

\section{RESPONSABILIDADE SOCIAL DAS ORGANIZAÇÕES EMPRESARIAIS}

Ao longo da história, sempre fora inegável que toda organização tem influência sobre a sociedade. Outrossim, indiscutível que o avanço das atividades econômicas, por via de consequência direta, fomenta o amadurecer da própria sociedade. Este amadurecer, aqui, tem duas vertentes: a um, significa que pela ordem natural, a atividade econômica, como geradora de riqueza que o é, desbordando-se do interesse personalíssimo do lucro individual do empresário, propicia mais acesso aos bens de consumo e melhor qualidade de vida, numa espécie de inclusão e desenvolvimento social de terceiros; a dois, pode significar que este amadurecer veio à duras penas, como efeito pedagógico de uma conduta que não se deveria adotar. Em ambos os casos, conclui-se que, o exercício de uma atividade econômica qualquer, por mais simples que for, tem implicações diretas no ambiente interno da organização, bem como, é fator decisivo no cenário externo.

Ao se alinhavar uma lógica de pensamento, ecoam algumas inquietações, tais como: se a empresa, enquanto organização existe para gerar lucros aos seus sócios-proprietários, pode existir também para promover o bem-estar social? Ademais, se o lucro aumenta quando os gastos diminuem, os acionistas estariam dispostos a ser socialmente responsáveis? (SOARES, 2008, p. 14).

Encontra-se, em que pese a complexidade do tema, fundamentos para debater a responsabilidade social de uma organização empresarial, tanto na Administração, quanto no Direito. Busca-se, atender à necessidade de justo equilíbrio entre as exigências da economia (atividade empresarial) e as do meio socioambiental.

A expressão responsabilidade social remonta ao século $\mathrm{XX}$, pois fora utilizada pelos americanos Charles Eliot (1906), Hakley (1907) e John Clark (1916). De modo específico com o objeto deste trabalho, há de consignar a abordagem de Oliver Sheldon, que em 1923, em seu 
livro The Philosophy of Management, defendeu a inclusão entre as preocupações da empresa, de outros objetivos além do lucro do acionista, como, por exemplo, da questão social (ARAÚJO, 2006, p. 30). Em complemento, destaca-se a ideia de que os negócios são centros vitais de poder e decisão e que as ações das empresas atingem a vida dos cidadãos em muitos pontos, razão pela qual as empresas devem compreender melhor seu impacto social, e que o desempenho social e ético deve ser avaliado por meio de auditorias (BOWEN, 1957, p. 03).

Afirmar, para a Administração, que as organizações têm responsabilidades sociais, significa dizer que elas têm a obrigação de agir no melhor interesse da sociedade, visando o bem-estar desta à medida que procura atingir seus próprios interesses (CHIAVENATO, 2003, p. 607). Dessa feita, segundo Maximiano, as organizações devem pautar sua ação pelo princípio do estágio pós-convencional desenvolvimento moral, onde, sob a batuta do idealismo moral, a

\footnotetext{
“conduta pessoal, grupal ou individual está fundamentada em princípios morais que reconhecem os direitos alheios, o impacto do comportamento sobre os outros, as gerações futuras (...), auto-realização por meio do respeito para consigo próprio e para com os outros" (2011, p. 392).
}

De outro lado, para o Direito, no momento em que se afirma ser a organização empresarial uma propriedade (privada), esta, por mandamento constitucional, haverá de cumprir sua função social (art. $5^{\circ}$, XXIII). Esta é exaustivamente tratada na Constituição, como por exemplo, nos artigos 170, III; 173, § 1, I; 182, § 2; 184, caput; e 185, parágrafo único. Nesse cenário, a função social funciona como o poder-dever de vincular a coisa (bem) a um objetivo determinado pelo interesse coletivo. Conclui que uma vez que "se está diante de um interesse coletivo, essa função social da propriedade corresponde a um poder-dever do proprietário, sancionável pela ordem jurídica" (COMPARATO, 1986, p. 75).

A perspectiva atual é outra, pois com o advento de uma nova realidade de exploração empresarial, segundo Wambier (2013, p. 165) “a empresa é entendida como a expressão de vontade do seu empresário e todos os que com ele colaboram, bem como da sociedade civil em que está inserida”. Na linha do art. 1.228, do Código Civil,

a propriedade é direito individual que assegura ao seu titular uma série de poderes e faculdades: usar, gozar, dispor e reivindicar, ou, resumidamente, jus vindicandi e jus abutendi, compreendido neste o jus disponendi. Ao lado dessas faculdades, os doutrinadores clássicos costumavam falar que o direito de propriedade tinha característica de plenitude, que permitiria toda espécie de poder lícito de utilização (JELINEK, 2006, p. 24) 
Hodiernamente, a obrigatoriedade do atendimento de sua função social, cuja definição é inseparável do requisito obrigatório do uso racional da propriedade e dos recursos ambientais que lhe são integrantes, impõe ao proprietário uma série de ações e abstenções. Como exemplo, não pode o proprietário causar contaminação do solo, construir em áreas de reserva legal ou em áreas de preservação permanente. Por esse entender,

por meio de nova interpretação do princípio da função social da empresa, juntamente
com o princípio da solidariedade, as empresas tornam-se tão responsáveis quanto o
Estado no que se refere a assegurar os direitos individuais e sociais, colaborando para
a melhora no aspecto econômico da sociedade na qual está inserida (WAMBIER,
2013, p. 165).

Há de se perceber que não precisa estar a função social positivada (encartada numa lei) para seja ela observada e cumprida pela organização social. Notadamente, quando a organização está inserida na busca pelo desenvolvimento sustentável e ladeada por steakholders. Deveras, reclama-se, mesmo que não haja provocação legal, que a empresa atente-se para deveres éticos e, mais ainda, pratique o exercício justo da atividade empresarial. O delineamento da responsabilidade social, portanto, chama mais atenção quando o hodierno cenário global impõe como estratégia empresarial, seja desenvolvida a cultura organizacional de praticar a atividade econômica pautando-se pelo desenvolvimento sustentável.

Com efeito, essa estratégia empresarial conducente com o desenvolvimento sustentável, frente à responsabilidade social da organização, requer mudança comportamental. E essa atitude constitui verdadeira destruição criadora, pois transformação qualitativa que revoluciona a estrutura econômica a partir de dentro, destruindo incessantemente o antigo e criando elementos novos (SCHUMPETER, 1961, p. 110). Ou melhor dizendo,

o capitalismo calcado na sustentabilidade, onde os atores do cenário econômico
sempre deverão estar atentos ao meio ambiente e ao social em suas ações econômicas,
não importando a teoria econômica adotada pelo Estado, podendo este ser liberal,
social ou neoliberal (SOUZA; PEIXOTO, 2018, p. 698)

É de se dizer: a organização empresarial que, mesmo ainda objetivando o lucro, se adequa e pratica de fato a livre iniciativa e exploração econômica com vista a exercer sua função social, pratica inovação. Ou seja, tem vantagem no cenário competitivo, pois a própria sociedade consumidora e usufrutuária dos bens e serviços pela organização produzidos e disponibilizados, reclama tal comportamento. 
Ao passo que as organizações refletem a imagem de máquinas, com toda sua estrutura burocrática e partes apenas especializadas - que, sobremaneira, uma vez retiradas ou deficitárias, implicam no funcionamento do todo -, tendem a cair no fracasso de seus objetivos, sobretudo, aqueles ligados às responsabilidades sociais. E a explicação para isso é que não se deve enxergar a organização social como um ente (instituição social) fechada e imutável: a sociedade e os próprios indivíduos que a compõe, tem natureza mutacional. Desse modo, melhor seria vê-las como organismos, pois, em analogia aos seres vivos, mais fácil se adequar aos diferentes ambientes decorrentes dessa interação, por meio de processo de compreensão e administração das necessidades. Em complemento, não se pode descurar da importância, nesse afã do desenvolvimento sustentável e das responsabilidades sociais, de a organização empresarial ter capacidade, como se um cérebro fosse, para o processamento de informações, aprendizagem e inteligência, com padrão crescente de refinamento da atividade econômica (MORGAN, 1996).

\section{CONCLUSÃO}

Pondo-se em paralelo noções do Direito e da Administração, emerge salutar analisar como o princípio do desenvolvimento sustentável se comporta como fator de obtenção do justo equilíbrio entre as exigências socioambientais e as da atividade econômica, com base na responsabilidade social das organizações empresariais.

Cediço que a ordem constitucional vigente assegura a todos o livre exercício de qualquer atividade econômica, e o faz após apontar a livre iniciativa como fundamento da República (art. $1^{\circ}$, IV) e colocar a propriedade como direito fundamental (art. $5^{\circ}, \mathrm{XXII}$ ), inclusive, a privada. Ocorre que, as empresas, enquanto organizações, por terem responsabilidades sociais, devem compreender melhor seu impacto social, e rever sua postura e desempenho, prestigiando o contexto ao qual está inserida e caracterizar-se como um sistema aberto e interativo com o seu meio.

A função social da propriedade, enquanto responsabilidade social da organização empresarial, não se limitando ao cumprimento dos deveres legais, mas à destinação efetivamente dada à propriedade, aponta que o sustentável desenvolvimento tem de estar relacionado, sobretudo, com a melhora da qualidade de vida e das liberdades que desfrutamos e, para isso, torna-se necessária a ação conjunta institucional.

Desse modo, a organização empresarial, ao praticar conduta fulcrada no desenvolvimento sustentável, portanto, investindo em responsabilidade social, consegue 
agregar valor e, para além de contribuir com a conservação do meio ambiente e dos steakholders, pode reverter isso a seu favor. Com efeito, se pode obter retorno direto à imagem institucional da organização, maior produtividade vinda da satisfação do empregado e fornecedores, etc., garantindo sua sobrevivência a longo prazo, e atender às necessidades do presente sem comprometer a possibilidade de as gerações futuras atenderem às suas necessidades.

\section{REFERÊNCIAS}

ARAÚJO, Marley Rosana Melo de. Responsabilidade social e a satisfação do consumidor: um estudo de caso. 2006, 192f. Tese (Doutorado em Psicologia). Universidade Federal do Pará, Belém, 2006. Disponível em < http://repositorio.ufpa.br/jspui/bitstream/2011/2479/1/Dissertacao_ResponsabilidadeSocialSat isfacao.pdf> Acesso em 25.03.2019.

BOWEN, Howard R. Responsabilidades sociais do homem de negócios. Rio de Janeiro: Civilização Brasileira, 1957.

BRASIL. Constituição (1988). Constituição da República Federativa do Brasil. Brasília, DF, 15 maio 1996. Disponível em: <

http://www.planalto.gov.br/ccivil_03/Constituicao/ConstituicaoCompilado.htm> Acesso em: 07.03.2019.

. Lei $\mathrm{n}^{\circ}$ 556, de 25 de junho de 1850. Institui o Código Comercial. Coleção de Leis do Brasil de 1850, T.11, pág. 57-238. Disponível em: <http://www.planalto.gov.br/ccivil_03/leis/L0556-1850.htm> Acesso em: 07.03.2019.

. Lei $n^{\circ}$ 6.938, de 31 de agosto de 1981. Dispõe sobre a Política Nacional do Meio Ambiente, seus fins e mecanismos de formulação e aplicação, e dá outras providências. Diário Oficial da União, Brasília, DF, 02 set. 1981. Disponível em: < http://www.planalto.gov.br/ccivil_03/leis/L6938.htm> Acesso em: 07.03.2019.

Lei $\mathrm{n}^{\circ} 10.406$, de 10 de janeiro de 2002. Institui o Código Civil. Diário Oficial da União, Brasília, DF, 11 jan. 2002. Disponível em:

<http://www.planalto.gov.br/ccivil_03/leis/2002/110406.htm> Acesso em: 07.03.2019.

. Supremo Tribunal Federal. ADI 3540 MC, Relator: Min. CELSO DE MELLO, Tribunal Pleno, julgado em 01.09.2005, Diário da Justiça de 03.02.2006.

BULGARELli, Waldírio. Tratado de Direito Empresarial. $2^{a}$ ed. Editora Atlas: São Paulo, 1995. Paulo, 1985.

Sociedades Comerciais - Empresa e Estabelecimento. $2^{a}$ ed. Editora Atlas: São 
CHIA VENATO, Idalberto. Empreendedorismo: dando asas ao espírito empreendedor. São Paulo: Saraiva, 2006.

Introdução à Teoria Geral da Administração. 7. ed. rev. e atual. Rio de Janeiro: Elsevier, $2003-5^{\circ}$ reimpressão.

CGEE - Centro de Gestão e Estudos Estratégicos. Economia verde para o desenvolvimento sustentável. Distrito Federal: Centro de Gestão e Estudos Estratégicos, 2012.

COMPARATO, Fábio Konder. Função Social da Propriedade dos Bens de Produção. Revista de Direito Mercantil, Industrial, Econômico e Financeiro, São Paulo, n. 63, p. 71-79, 1986.

DINIZ, Maria Helena. Manual de Direito Civil. São Paulo: Saraiva, 2011.

GUimarẽes, MÁRCIO. Teoria Geral da Empresa. Material didático 2016.1. Rio de Janeiro: FGV, 2016. Disponível em:

$<$ http://direitorio.fgv.br/sites/direitorio.fgv.br/files/u1882/teoria_geral_da_empresa_20161.pdf> Acesso em 20.03.2019.

HOFF, Débora Nayar. A construção do desenvolvimento sustentável através das relações entre as organizações e seus steakholders: a proposição de uma estrutura analítica. 2008, 425f. Tese (Doutorado em Agronegócios). Universidade Federal do Rio Grande do Sul, Porto Alegre, 2008. Disponível em < https://www.google.com.br/url? sa=t\&rct=j\&q=\&esrc=s\&source=web\&cd=1\&cad=rja\&uact=

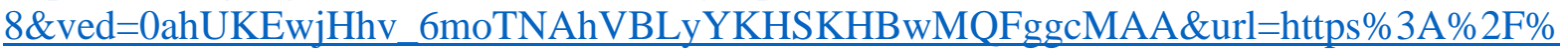
2Fwww.lume.ufrgs.br\%2Fbitstream\%2Fhandle\%2F10183\%2F13395\%2F000648136.pdf\%3F sequence\%3D1\&usg=AFQjCNGeIjdX8szDZqfVrYGkAJj_c-DYfA\&sig2=8nBW5aAQpZ0j1FxVhKP7Q\&bvm=bv.123325700,d.eWE> Acesso em 24.03.2019.

JELINEK, Rochelle. O princípio da função social da propriedade e sua repercussão sobre o sistema do código civil. Disponível em

<http://www.mprs.mp.br/areas/urbanistico/arquivos/rochelle.pdf> . Acesso em 15.03.2019.

LENZA, Pedro. Direito Constitucional Esquematizado. 18. ed. rev., atual. e ampl. São Paulo: Saraiva, 2014.

KANAANE, Roberto. Comportamento humano nas organizações: o homem rumo ao século XXI. São Paulo: Atlas, 1994.

MAXIMIANO, Antonio Cesar Amaru. Introdução à Administração. 8. ed. rev. e ampl. São Paulo: Atlas, 2011.

MORGAN, Gareth. Imagens da organização. São Paulo: Atlas, 1996.

SCHUMPETER, Joseph A. Capitalismo, Socialismo e Democracia. Tradução de Ruy Jugmann. Editado por George Allen e Unwin Ltda. Rio de Janeiro: Editora Fundo de Cultura, 1961. 
. A Teoria do desenvolvimento econômico. Tradução de Maria Sílvia Possas. São

Paulo: Editora Nova Cultural (Coleção Os Economistas), 1997.

SOARES, Laíla Rodrigues. Responsabilidade social empresarial: uma análise dos modelos teóricos-conceituais. 2008, 110f. Dissertação (Mestrado em Administração). Universidade Federal da Bahia, Salvador, 2008. Disponível em

<http://www.adm.ufba.br/sites/default/files/publicacao/arquivo/dissertaao_de_laila_rodrigues _soares.pdf $>$ Acesso em 25.03.2019.

SOUZA, Paulo Roberto Pereira de; DE CARVALHO PEIXOTO, Leonardo. A responsabilidade dos diretores em relação as externalidades ambientais. Revista Argumentum-Argumentum Journal of Law, v. 19, n. 3, p. 691-709, 2018.

VIDO, Elisabete. Curso de Direito Empresarial. 4. ed. rev., atual. e ampl. São Paulo: Revistas dos Tribunais, 2015.

VILANI, Rodrigo Machado. A aplicação do conceito constitucional de desenvolvimento sustentável sob a perspectiva do STJ e STF. Revista Brasileira de Direito Constitucional, São Paulo, n. 13, p. 63-79, jan./jun. 2009.

WAMBIER, Luciane. A função social da empresa e o princípio da solidariedade: instrumentos de cristalização dos valores sociais na estrutura jurídico-trabalhista. Revista do Tribunal Regional do Trabalho da 15ª Região. Campinas, n. 42, p. 157-172, 2013. Disponível em <http://portal.trt15.jus.br/documents/124965/1402934/Rev.42_art.9/8e98c931a6ee-477c-8464-5f1507fbd86e>. Acesso em 29.03.2019. 